\title{
Revealing the sedative-hypnotic effect of the extracts of herb pair Semen Ziziphi spinosae and Radix Polygalae and related mechanisms through experiments and metabolomics approach
}

\author{
Hong Luo ${ }^{\dagger}$, Sheng-jie Sun ${ }^{\dagger}$, Yan Wang and Ying-li Wang ${ }^{*}$
}

\begin{abstract}
Background: Semen Ziziphi spinosae and Radix Polygalae, two herbs commonly used together in Traditional Chinese Medicine for the treatment of insomnia and anxiety. The study aims to study the sedative-hypnotic effect of the active components of the herbal pair, the possible mechanisms of such effect, and related metabolic pathways in vivo.

Methods: The sedative and hypnotic effect of the active components (EI30) of the herbal pair was studied by recording influence on the proportion of sleeping within $30 \mathrm{~min}$, sleep latency and sleep length of pentobarbital sodium-induced sleeping on mice. Possible mechanisms of the sedative-hypnotic effect of the active components were investigated by measuring the content of neurotransmitters in the total protein of mice brain tissue. The main chemical compounds of the herbal pair were identified by Liquid Chromatography-Mass Spectrometry (LC-MS). Serum samples of mice were studied, and related differential metabolites between the normal group and model group, and between model group and treatment group were identified by Gas Chromatography Time-Of-Flight Mass Spectrometry (GC-TOF-MS), Principal Components Analysis (PCA), and Orthogonal Projections to Latent Structures Discriminant Analysis (OPLS-DA).

(Continued on next page)
\end{abstract}

\footnotetext{
*Correspondence: wyltyut@163.com

${ }^{+}$Hong Luo and Sheng-jie Sun contributed equally to this work.

School of Chinese Materia Medica, Shanxi University of Chinese Medicine,

Daxue Street, No.121, Jinzhong, Shanxi, China
}

C C The Author(s). 2020 Open Access This article is licensed under a Creative Commons Attribution 4.0 International License, which permits use, sharing, adaptation, distribution and reproduction in any medium or format, as long as you give appropriate credit to the original author(s) and the source, provide a link to the Creative Commons licence, and indicate if changes were made. The images or other third party material in this article are included in the article's Creative Commons licence, unless indicated otherwise in a credit line to the material. If material is not included in the article's Creative Commons licence and your intended use is not permitted by statutory regulation or exceeds the permitted use, you will need to obtain permission directly from the copyright holder. To view a copy of this licence, visit http://creativecommons.org/licenses/by/4.0/ The Creative Commons Public Domain Dedication waiver (http://creativecommons.org/publicdomain/zero/1.0/) applies to the data made available in this article, unless otherwise stated in a credit line to the data. 
(Continued from previous page)

Results: Compared with the control group, high dose El30 group and the Clonazepam group were with significantly higher proportions of sleep within $30 \mathrm{~min}(P=0.027$ and 0.005 respectively). Compared with the control group, all of the high, medium and low dose of El30 groups were with significantly shorter sleep latency $(P<0.01)$ and prolonged sleeping time $(P<0.01)$. The herbal pair has good sedative-hypnotic effects, although it is weaker than the effect of Clonazepam. The sedative-hypnotic effect of El30 is possibly related to the adjustment of neurotransmitters 5-hydroxytryptamine (5-HT), norepinephrine (NE), and dopamine (DA) in the total protein of mice brain tissue. There are five metabolic pathways in vivo most related to the sedative-hypnotic effect of El30, and they are biosynthesis of valine, leucine, and isoleucine, metabolism of glyceride, metabolism of alanine, aspartic acid and glutamic acid, metabolism of phenylalanine, and metabolism of cysteine and methionine.

Conclusions: This study reveals the mechanisms of sedative and hypnotic effects of herbal pair Semen Ziziphi spinosae and Radix Polygalae by using metabolomics methods. This study provides a basis for further development and utilization of this herbal pair.

Keywords: GC-TOF-MS, Herbal pair, Sedative-hypnotic effect, Serum metabolomics approach, Semen Ziziphi spinosae and Radix Polygalae

\section{Background}

Semen Ziziphi spinosae, the seed of Ziziphus jujuba Mill. var. spinosa (Bunge) $\mathrm{Hu}$ ex H. F. Chow, mainly contains substances such as flavonoids, saponins, alkaloids, volatile oils, amino acids [1, 2]. Semen Ziziphi spinosae has been proven by previous studies to have medicinal functions of sedative-hypnotic effect, antianxiety effect [3], anti-depression effect [4], hypoglycemic action [5], anti-dementia effect [6], and effect of strengthening the immune system [7], etc. The total flavonoids and total saponins in Semen Ziziphi spinosae are the principal effective components for sedative and hypnotic effects $[8,9]$.

One of the main effective compounds for the sedative and hypnotic effects of Semen Ziziphi spinosae is spino$\sin$, which is a flavonoid glycoside monomer [10]. Spinosin can induce sleep in mice [11], prolong the length of pentobarbital induced sleep and reduce sleep latency in rats [12]. A previous animal experiment has shown that spinosin has anxiolytic-like effects in mice. High doses of spinosin ( $5 \mathrm{mg} / \mathrm{kg} /$ day) on mice could significantly increase the number of times entering into the open arms of the elevated plus-maze, the proportion of time spent on the open arms, the number of transitions between light and dark boxes, and time spent in the light compartment [13].

Jujuboside A found in Semen Ziziphi spinosae had been proven by a previous animal experiment to have sedative effects. A study showed that jujuboside A could reduce the activity of drosophilae melanogaster during the day and prolong their sleep time [14].

The alkaloids in Semen Ziziphi spinosae also showed obvious sedative effects, according to a previous study conducted on mice. The alkaloids in Semen Ziziphi spinosae can significantly inhibit spontaneous activities in mice, shorten the latency of sleep induced by a suprathreshold dose pentobarbital sodium, and prolong the sleep duration [15].

Radix Polygalae, dry roots of Polygala tenuifolia Willd or Polygala sibirica L. mainly contain substances such as saponins, sugar esters, volatile oils, organic acids, and small amounts of alkaloids and flavonol glycosides [16-19]. Radix Polygalae is reported to have effects of sedation and hypnosis, memoryenhancing [20], anti-dementia [21], anti-aging [22], and anti-inflammatory [23].

Senegenin is the active component for the sedative and hypnotic effects of Radix Polygalae [24]. Tenuifolin, a kind of senegenin, has been proven to have sedative effects. In a study, mice were intragastrically injected with tenuifolin at doses of 20,40 , and $80 \mathrm{mg} / \mathrm{kg}$, and the results showed that $40 \mathrm{mg} / \mathrm{kg}$ and $80 \mathrm{mg} / \mathrm{kg}$ doses groups were with significantly increased the non-rem sleep time, rem sleep time, and total sleep time [25].

Other substances in Radix Polygalae had been proven to have sedative effects as well. The sedative-hypnotic effects of 3,4,5-Trimethoxycinnamic acid (TMAC), a compound derived from Radix Polygalae, were proven to act via increasing the chloridion influx and activating glutamic acid decarboxylase and $\gamma$-subunit of $\mathrm{GABA}_{\mathrm{A}}$ receptors in the cerebellar granule cells [26].

Studies have shown that 3,6'-disinapoyl sucrose derived from Radix Polygalae also has sedative effects. It has a definite antidepressant effect and can improve the behavioral indexes of depression mice. Its effects may act via participating in the regulation of apoptosis genes, inhibiting apoptosis, and promoting nerve cell regeneration [27]. Another way for it to promote nerve regeneration and protection may be to participate in the regulation of cellular oxidative stress by improving the body's antioxidant capacity and free radical scavenging capacity [27]. 
In traditional Chinese medicine, Semen Ziziphi spinosae and Radix Polygalae are commonly used as a herbal pair. A herbal pair refers to two herbs used together in clinical practice. They can act synergistically to enhance herb effects or relieve toxicity [28]. The results of preliminary research conducted by authors of this study showed that water extraction liquid of both Radix Polygalae and Semen Ziziphi spinosae could improve the proportion of sleep in mice within $30 \mathrm{~min}$, which was consistent with previous studies $[8,10]$. Moreover, the water extraction liquid of the herbal pair showed a stronger hypnotic effect, which indicated that the study on the combination of the two herbs is significant.

At present, there are many studies on the chemical components related to the sedative-hypnotic effect of the two herbs. The mechanisms of such effect of Semen Ziziphi spinosae have already been studied by the use of method of metabolomics [29]. However, few studies were conducted to study the sedative-hypnotic effects of their combination and the possible mechanisms of these effects.

In this study, the herbal pair Semen Ziziphi spinosae and Radix Polygalae were the research object, and the active parts of this herb pair (total flavonoids and total saponins) were acquired by D101 macroporous adsorption resin to study its sedative-hypnotic effect. The primary objective of this research was to study the sedative-hypnotic effect of this herbal pair and explore possible mechanisms. The secondary objectives were to study the sedative-hypnotic effect of the herbal pair by animal experiments, identify the main effective chemical compounds of the herbal pair, investigate the mechanisms of its sedative-hypnotic effect by measuring the levels of neurotransmitters in mice brain tissue and by methods of serum metabolomics.

\section{Methods}

\section{Test drugs and instruments}

Fried Semen Ziziphi spinosae (Lot: 160901) was purchased from Bozhou Jingyi Traditional Chinese Medicine Prepared Drug Pieces Factory. Radix Polygalae (Lot: 1601001) was purchased from Hebei Quantai Pharmaceutical Co., Ltd. Sodium pentobarbital (Lot: 140424) was purchased from Shanghai Ika Bio-Technology Co., Ltd. Para-chlorophenylalanine (PCPA) (Lot: C0253) was purchased from Tokyo Chemical Co., Ltd., Japan. Assay kits (201709) of 5-HT, NE, GABA, DA were purchased from Shanghai Chuangsai Technology Co., Ltd. BCA Protein Assay Kit (20170913) was purchased from Beijing Suolaibao Technology Co., Ltd. Senegenin standard (Lot: 160107) was purchased from Shanghai Ronghe Medical Technology Co., Ltd. Jujuboside A (Lot: wkq16053003; CAS: 72063-39-9) and spinosin standard (Lot: wkq16062804) were purchased from Sichuan
Victory Biotechnology Co., Ltd. D101 macroporous adsorption resin was purchased from Shanghai Jinsui Biotechnology Co., Ltd.

Instruments used in this study include Versamax Microplate Reader (Miguel Molecular Instruments Shanghai Co., Ltd.), high performance liquid chromatography (Agilent, USA), ELSD6000 evaporative light scattering detector, 7890B gas chromatography (Agilent), PEGASUS HT mass spectrometer (LECO), DB-5MS column (Agilent, $30 \mathrm{~m} \times 250 \mu \mathrm{m} \times 0.25 \mu \mathrm{m}$ ), Heraeus Fresco 17 centrifuge (Thermo Fisher Scientific), Forma 900 series ultra-low temperature refrigerator (Thermo Fisher Scientific), TNG-T98 vacuum dryer (Taicang Huamei Biochemical Instrument Factory), XHF-DY high speed disperser (Ningbo Xinzhi Biotechnology Co., Ltd.), CP24C analytical balance (Shanghai Ohaus Co., Ltd.), SC-02 low speed centrifuge (Anhui Zhongke Zhongjia Scientific Instrument Co., Ltd.), TU-1810 UV-Visible spectrophotometer (Beijing Pu Analysis General Instrument Co., Ltd.), Q Exactive Focus Orbitrap LC-MS/M (Thermo Fisher Scientific).

\section{Experimental animals}

The Medical Ethics Committee of Shanxi University of Chinese Medicine gave ethical approval for using experimental animals for this study (Approval number: 2019LL129). All experimental procedures in this study were under the ethical standards of the Medical Ethics Committee of Shanxi University of Chinese Medicine.

Experimental animals used in this study were SPF Kunming mouse weighing 18-22 g, half male and hale female (certificate number: 0009175; license number: SCXK military 2012-0004, purchased from Experimental Animal Center of the Chinese Academy of Military Medical Sciences). Experimental mice can be used in basic experiments such as pharmacological experiments and disease model construction. All mice used in the study were euthanized by cervical dislocation.

Housing and husbandry conditions: The experimental mice were housed in small plastic cages with observable metal lids. Each cage housed six to eight mice. The cages were equipped with plastic water bottles with drinking water pipes, with purchased clean and dry mat materials were used. The mouse feed was purchased nutrient pellet feed. The housing temperature and relative humidity were kept at 18 to $22^{\circ} \mathrm{C}$ and 50 to $60 \%$, respectively. The feed and water were refilled every afternoon, and the appearances of the animals were checked each morning to determine their health status by criteria such as healthy appetite, quick response, smooth body hair, and black grain-shaped feces. 


\section{Preparation of effective components}

Fried Semen Ziziphi spinosae and Radix Polygalae were crushed into coarse powder and mixed by the mass ratio of 2:1. The mixture was degreased with petroleum ether to get the powder. The powder was then extracted twice with ten times $65 \%$ ethanol at $70{ }^{\circ} \mathrm{C}$ (each time for one hour). The extracted solution was collected and injected onto the D101 macroporous resin to separate and purify the extract.

Gradient elution was performed with distilled water 8 $\mathrm{BV}, 30$ and $50 \%$ ethanol $8 \mathrm{BV}, 70 \%$ ethanol $4 \mathrm{BV}$ at a flow rate of $1 \mathrm{BV} / \mathrm{h}$. The solid obtained by $30 \%$ ethanol eluent was used as the effective components (part) of the experiment (named EI30), and its total flavonoids and saponins were analyzed.

\section{Study on the sedative-hypnotic effect of El30}

Sixty mice were randomly divided into five groups (half male and half female in each group) by the aid of a random table, namely control group, Clonazepam group, EI30 high-dose group, EI30 medium-dose group, and EI30 low-dose group. The doses in the three EI30 groups were calculated by the amount of flavonoid content in the freeze-dried powder of EI30, which was $13.8 \mathrm{mg} \cdot \mathrm{kg}^{-1}$ for the high-dose group, $6.9 \mathrm{mg} \cdot \mathrm{kg}^{-1}$ for the mediumdose group and $3.45 \mathrm{mg} \cdot \mathrm{kg}^{-1}$ for the low-dose group. The Clonazepam group was the positive control group and was given Clonazepam at a dose of $0.01 \mathrm{mg} \cdot \mathrm{kg}^{-1}$. The control group was given the same amount of distilled water. Each group received gavage once per day for six consecutive days.

In the subthreshold dose sleep test, $30 \mathrm{~min}$ after the administration of the last dose, all animals were injected intraperitoneally with pentobarbital sodium for 25 $\mathrm{mg} \cdot \mathrm{kg}^{-1}$. The percentage of mice falling asleep within the next $30 \mathrm{~min}$ was recorded.

In the suprathreshold dose sleep latency and duration test, normal gavage was performed on the seventh and eighth days, and all mice fasted for $12 \mathrm{~h}$ before the test. After $30 \mathrm{~min}$ of the last administration of treatments, 50 $\mathrm{mg} \cdot \mathrm{kg}^{-1}$ of pentobarbital sodium was injected intraperitoneally. The sleep latency and sleep time of each mouse were recorded with the disappearance of the righting reflex as the indicator for falling asleep.

\section{Study on the mechanisms using PCPA induced insomnia model}

\section{Preparation of PCPA induced insomnia mice model}

After a week of adaptive feeding, mice were intraperitoneally injected with $350 \mathrm{mg} \cdot \mathrm{kg}^{-1}$ PCPA once a day for three consecutive days. The animals showed a loss of circadian rhythm and were active during the day, suggesting that the insomnia model was successfully made. 32 model mice were randomly divided into 4 groups $(8$ mice in each group) by the aid of a random table: (1) the model control group; (2) high dose EI30 group (13.8 $\left.\mathrm{mg} \cdot \mathrm{kg}^{-1}, 3\right)$ middle dose EI30 group $\left(6.9 \mathrm{mg} \cdot \mathrm{kg}^{-1}, 4\right)$ low dose EI30 group $\left(3.45 \mathrm{mg} \cdot \mathrm{kg}^{-1}\right)$. Eight normal mice were taken as the normal control group (given an equal amount of distilled water). The mice were given oral gavage once a day for 6 days.

\section{Study on the mechanisms of the sedative-hypnotic effect of EI30}

Before the last administration of treatments, the mice fasted for $12 \mathrm{~h} .6 \mathrm{~h}$ after the last administration of treatments, brain tissues of the mice were extracted and weighed. Nine times normal saline was added to the brain tissue, which was then prepared into homogenate by high-speed disperser. The homogenate was centrifuged at $3500 \mathrm{r} \bullet \mathrm{min}^{-1}$ for $10 \mathrm{~min}$, and the supernatant was taken to obtain $10 \%$ brain tissue homogenate. The contents of 5-hydroxytryptamine (5-HT), norepinephrine (NE), dopamine (DA), and Gamma-aminobutyric acid (GABA) in the brain tissue homogenate were determined by ELISA. The possible mechanisms of the sedative-hypnotic effect of EI30 were investigated by comparing 5-HT, DA, NE, and GABA content of the brain tissues of mice in each group.

\section{Analysis of effective components Preparation of reference solution}

Spinosin $(2.3 \mathrm{mg})$ and senegenin $(2.7 \mathrm{mg})$ were accurately weighed and placed in two $10-\mathrm{mL}$ volumetric flasks, and volume was adjusted to with methanol and mixed well. $0.23 \mathrm{mg} \bullet \mathrm{mL}^{-1}$ and $0.27 \mathrm{mg} \bullet \mathrm{mL}^{-1}$ reference solutions were obtained and were filtered with $0.45 \mu \mathrm{m}$ microporous membrane filters before use.

\section{Preparation of sample solution}

$43.2 \mathrm{mg}$ EI30 freeze-dried powder was accurately weighed and placed in a $10-\mathrm{ml}$ volumetric flask. The volume was made up to with methanol. The solution was filtered with a $0.45 \mu \mathrm{m}$ membrane filter before used to determine the content of spinosin.

EI30 freeze-dried powder $(0.271 \mathrm{~g})$ was dissolved with $20 \mathrm{~mL} 10 \%$ hydrochloric acid, and the solution was refluxed in a boiling water bath for $2 \mathrm{~h}$ to obtain brown precipitate on filter paper. Then, the filter paper was washed with a small amount of methanol several times to make the precipitate dissolved and filtered into a 10 $\mathrm{mL}$ volumetric flask. Methanol was used to adjust to volume. The solution was filtered with a $0.45 \mu \mathrm{m}$ membrane filter before being used to measure the content of senegenin. 


\section{Identification of the chemical compounds of the herbal pair}

The main chemical components of the effective part EI30 were identified by LC-MS using Q Exactive Focus MS 2.5.4 by Thermo Fisher Scientific. The chromatographic separation was performed on Venusil XBP C18 column $(4.6 \mathrm{~mm} \times 250 \mathrm{~mm}, 5 \mu \mathrm{m})$ at $30^{\circ} \mathrm{C}$ with a volume flow rate of $1 \mathrm{~mL} \cdot \mathrm{min}^{-1}$ and the injection volume of $10 \mu \mathrm{L}$.

For spinosin [30]: The mobile phase was a gradient elution system of A (acetonitrile) and B (aqueous), and the elution was programmed as follows: $12-19 \%$ A for 0-10 min; $19-20 \%$ A for $10-16 \mathrm{~min}$; $20-100 \%$ A for 16-22 min; A $100 \%$ for $22-30$ min; $100-12 \%$ A for $30-$ $35 \mathrm{~min}$. The detected wavelength was $335 \mathrm{~nm}$.

For senegenin [31]: The mobile phase was a gradient elution system of A (acetonitrile) and B ( $0.1 \%$ phosphoric acid solution). The elution was programmed as follows: $10 \%$ A for $0-10 \mathrm{~min}$; $10-65 \%$ A for $10-30 \mathrm{~min}$; $65 \%$ A for $30-50 \mathrm{~min}$. The detected wavelength was 210 $\mathrm{nm}$.

For jujuboside A [30]: The mobile phase was a gradient elution system of A (acetonitrile) and B (aqueous). The elution was programmed as follows: $20-40 \%$ A for 0-15 min; 40\% A for $15-28 \mathrm{~min} ; 40-70 \%$ A for $28-30$ $\min ; 70 \% \mathrm{~A}-100 \%$ A for $30-32 \mathrm{~min}$.

$1,3,4,5$, and $6 \mu \mathrm{L}$ spinosin reference solutions and 1 , $2,4,6,8,10$, and $20 \mu \mathrm{L}$ senegenin reference solutions were precisely taken and analyzed under chromatographic conditions described above. Peak areas were recorded, and the standard curves using injection volume as the abscissa $(\mathrm{X})$ and the peak area as the ordinate $(\mathrm{Y})$ were obtained. The regression equation for spinosin was $\mathrm{Y}_{1}=2360 \mathrm{X}_{1}+4.8946, \mathrm{r}_{1}=0.9997$. There was a clear linear relationship within the injection volume range of $0.2245 \mathrm{~g}$ to $1.3542 \mathrm{~g}$. The regression equation for senegenin was $\mathrm{Y}_{2}=1279.1 \mathrm{X}_{2}+45.453, \mathrm{r}_{2}=0.9999$. The linear relationship was clear within the range of $0.2619 \mathrm{~g}$ to $5.238 \mathrm{~g}$. According to the analysis, the spinosin content in EI30 was 1.61\%, and the senegenin content in EI30 was $0.24 \%$. Jujuboside A was not detected in EI30.

\section{Study on the mechanisms of the sedative-hypnotic effect of El30 by methods of serum metabolomics Serum metabolite extraction and derivation}

Serum samples of normal group, PCPA insomnia model group, and EI30 high dose group were studied. $100 \mu \mathrm{L}$ sample was taken from each group and put into three $1.5 \mathrm{~mL}$ EP tubes. Then, $0.35 \mathrm{~mL}$ methanol-chloroform and $20 \mu \mathrm{L}$ of L-2-Chlorophenylalanine $(1 \mathrm{mg} / \mathrm{mL}$ stock in $\mathrm{dH}_{2} \mathrm{O}$ ) were added to the EP tubes. The samples were swirled for 30 s mix thoroughly, after which they were kept at $-20^{\circ} \mathrm{C}$ for $10 \mathrm{~min}$ before being centrifuged for $15 \mathrm{~min}$ with a speed of $12,000 \mathrm{rpm}$, at $4{ }^{\circ} \mathrm{C}$.
Subsequently, $0.4 \mathrm{~mL}$ supernate from each EP tube was transferred into $2 \mathrm{~mL}$ injection vials. $15 \mu \mathrm{L}$ from each sample was taken and pooled as the quality control (QC) sample.

All the above samples in injection vials were dried entirely in a vacuum concentrator without heating. Then, $60 \mu \mathrm{L}$ methoxymethyl amine salt (dissolved in pyridine, with a final concentration of $20 \mathrm{mg} / \mathrm{mL}$ ) was added, and the mixtures were incubated for $30 \mathrm{~min}$ at $80^{\circ} \mathrm{C}$. After that, $80 \mu \mathrm{L}$ of the BSTFA regent (containing $1 \%$ tetrachloro-4-methylsulfonyl, vol/vol) was added into the mixture, which was then being incubated for $1.5 \mathrm{~h}$ at $70{ }^{\circ} \mathrm{C}$. Later, $10 \mu \mathrm{L}$ FAMEs (Standard mixture of fatty acid methyl esters, $1 \mathrm{mg} / \mathrm{mL}$ stock in chloroform C8C16) was added. After cooling to room temperature, all samples were analyzed by GC-TOF-MS [32].

\section{GC-TOF-MS data collection on serum metabolite}

GC-TOF-MS analysis was performed using an Agilent 7890 gas chromatograph system coupled with a Pegasus HT time-of-flight mass spectrometer (GC-TOF-MS), which used a DB-5MS capillary column $(30 \mathrm{~m} \times 250 \mu \mathrm{m}$ inner diameter, $0.25 \mu \mathrm{m}$ film thickness, J\&W Scientific, Folsom, CA, USA) [32]. The specific analysis conditions of GC-TOF-MS were as follows: Injection volume: $1 \mu \mathrm{L}$; Mode: splitless; Front inlet purge flow: $3 \mathrm{~mL} \cdot \mathrm{min}^{-1}$; Gas flow rate through column: $1 \mathrm{~mL} \cdot \mathrm{min}^{-1}$; Temperature: initially kept at $50{ }^{\circ} \mathrm{C}$ for $1 \mathrm{~min}$, then raised to $310{ }^{\circ} \mathrm{C}$ at a rate of $20^{\circ} \mathrm{C} / \mathrm{min}$ and kept at $310^{\circ} \mathrm{C}$ for $6 \mathrm{~min}$; Injection temperature: $280^{\circ} \mathrm{C}$; Transfer line temperature: $280{ }^{\circ} \mathrm{C}$; Ion source temperature: $250{ }^{\circ} \mathrm{C}$; Ionization voltage: -70 ev; Scanning mode: $50-500 \mathrm{~m} / \mathrm{z}$; Scanning rate: 20 spectra per second; Solvent delay: $366 \mathrm{~s}$.

\section{Mass spectrometer (MS) data processing and analysis}

The MS data were put into Chroma TOF 4.3X software (LECO Corporation) for analysis, such as peak detection, baselines correlation, deconvolution analysis, and peak list alignment. For metabolites identification, the LECOFiehn database (library for mass spectrum and retention index) was used. Peaks with the detection rate of less than $50 \%$, or relative standard deviation (RSD) $>30 \%$ in the QC sample were removed. The raw data were preprocessed, and only the peak area data with missing values less than $50 \%$ in all groups were retained. Then the missing values were filled with $1 / 2$ of the minimum value. Finally, the internal standard method was used to normalize the data for statistical analysis.

The processed data were imported into SIMCA14.1 software for Principal Component Analysis (PCA), which revealed the distribution of metabolite in mice serum samples. To further investigate separations between groups and which variables were account for the separations (identify effective biomarkers), Orthogonal 
Projections to Latent Structures discriminant analysis (OPLS-DA) was performed to get score scatter plots between groups. Permutation tests were used to verify the validity of the OPLS-DA model. $\mathrm{R}^{2}$ and $\mathrm{Q}^{2}$ were used to express the validity of the OPLS-DA model. Variable importance projection (VIP) value of the first principle component, together with results of Student's $t$-test were obtained to determine differential metabolites that are significant. Variables with high VIP values $(>1.0)$ and statistical significance $(P<0.05)$ were identified as potential differential metabolites [33, 34]. Those potential differential metabolites were also visualized by volcanic maps. The metabolic pathways related to those identified differential metabolites were predicted and explored by MetaboAnalyst 3.0 (Http://www.metaboanalyst.ca/) and databases KEGG (https://www.genome.jp/kegg/).

\section{Results}

\section{Sedative-hypnotic effect of El30}

All the animals in the control group, Clonazepam group and each EI30 group were included in the data analysis. SPSS13.0 was used for analysis, and according to the type the data, Fisher's exact tests were performed to compare the proportion of mice sleeping within $30 \mathrm{~min}$ between the control groups and each EI30 group. As shown in Table 1, compared with the control group, the EI30 high-dose group and the Clonazepam group were with significantly higher proportions of mice sleeping within $30 \mathrm{~min} \quad(P=0.027$ and $P=0.005$ respectively). Medium-dose and low-dose groups showed relatively weaker effects $(P>0.05)$.

Student's $t$-tests were performed to compare sleep latency and duration between the control groups and each EI30 group. Results in Table 2 shows that compared with the control group, the Clonazepam group, and all three EI30 groups were with significantly shorter sleep latency $(P<0.01)$ and longer sleeping duration $(P<0.01)$.

\section{Effect of El30 on 5-HT, NE, DA, and GABA in brain tissue of mice}

PCPA is a synthetic inhibitor of 5-HT. Compared with the normal group, the content of 5-HT in total protein in brain tissue of mice in the model group was significantly lower, and the content of excitatory neurotransmitters NE and DA in total protein was higher in the model group, suggesting the models were produced successfully (As can be seen in Table 3 and Table 4).

Tables 3 and 4 demonstrate the contents of neurotransmitters 5-HT, GABA, NE, and DA in the brain tissues of mice. Compared with the model group, the content of 5HT in the total protein in brain tissue of mice was significantly higher in all the three EI30 groups $(P<0.01)$. The content of NE in the total protein was significantly lower in the low-dose EI30 group $(P<0.01)$, and the content of $\mathrm{DA}$ in the total protein was significantly lower in the medium-dose group $(P<0.05)$. The content of GABA was significantly lower for the high-dose group $(P<0.05)$.

\section{Identified compounds by LC-MS}

Eleven main compounds were identified in EI30 (the effective components of the herbal pair) by LC-MS. The results are shown in Table 5.

\section{GC-TOF-MS results of all serum samples and results of PCA}

GC-TOF-MS results of serum samples for normal group, model group, and EI30 high-dose group are shown in Fig. 1.

Based on GC-MS results of different groups' serum samples, PCA, an unsupervised multivariable data analysis method, were first used to comprehensively analyze and visualize data from all experiment groups [35]. Results of PCA are shown in Fig. 2. Abscissa t[1] and ordinate $t[2]$ represent the scores of the principal components ranking first and second, respectively. Scatters with different colors and shapes represent different sample groups. As can be seen from Fig. 2, the results of all samples were basically within the Hoteling's $\mathrm{T}^{2}$ ellipse (95\%). However, there were no distinct differences between any of the two groups, and this is because of the characteristics of the GC-TOF-MS metabolite profiling data were of a large number of metabolites but coming from relatively small samples [36]. Among these variables, there were not only differential variables but also undifferentiated variables. As a result, in the PCA model, the differential variables were not separated and visualized well, and therefore cannot be further interpreted. The results of PCA need to be further studied.

Table 1 Effect of El30 on the proportion of mice sleeping within $30 \mathrm{~min}$

\begin{tabular}{lllll}
\hline Group & Dosage $/ \mathrm{mg}^{\mathrm{kg}}{ }^{-1}$ & Number of mice & Number of sleeping within 30 min & Proportion of mice sleeping within 30 min $/ \%$ \\
\hline Control group & - & 12 & 5 & 42 \\
Clonazepam & 0.01 & 12 & 11 & $92^{*}$ \\
El30 high-dose group & 13.8 & 12 & 11 & $92^{*}$ \\
El30 medium-dose group & 6.9 & 12 & 10 & 83 \\
El30 low-dose group & 3.45 & 12 & 10 & 83
\end{tabular}


Table 2 Effect of El30 on sleep latency and duration $(\bar{x} \pm s)$

\begin{tabular}{llll}
\hline Group & Dosage $/\left(\mathrm{mg}^{\mathrm{kg}}{ }^{-1}\right)$ & Sleep latency /min & Sleep duration/min \\
\hline Control group & - & $41.2 \pm 19.8$ & $2.8 \pm 3.1$ \\
Clonazepam & 0.01 & $2.78 \pm 0.83^{* *}$ & $142.5 \pm 13.44^{* *}$ \\
El30 high-dose group & 13.8 & $4.5 \pm 2.4^{* * \# \#}$ & $18.7 \pm 11.7^{* *}$ \\
El30 medium-dose group & 6.9 & $4.0 \pm 1.9^{* * \# \#}$ & $10.1 \pm 4.5^{* *}$ \\
El30 low-dose group & 3.45 & $6.8 \pm 1.9^{* * \# \#}$ & $8.6 \pm 2.4^{* *}$ \\
\hline
\end{tabular}

Note:** compared with the control group, $P<0.01 .{ }^{\# \#}$ compared with the active control group, $P<0.01$

\section{Results of OPLS-DA}

To find out the relevant variables reflecting differences between groups, the OPLS-DA model was subsequently used [37]. The results are shown in Figs. 3, 4, 5 and 6. Figures 3 and 4 are score scatter plots of the analysis results between the normal group and the model group and between the model group and EI30 high-dose group. In these two figures, $t[1]$ and $t_{0}[1]$ respectively represent the score of the first predictive principal component and the score of the orthogonal principal component, which captures variations between groups. Scatters of different shapes and colors represent different sample groups. As can be seen from the two figures, there were systematic differences in metabolites between the normal group and the model group, and between the model group and EI30 high-dose group, indicating that first the PCPA induced insomnia mice model was successfully made, and EI30 had obvious effects on the model [38]. Compared with the results of PCA, the OPLS-DA model showed the differences between sample groups more clearly. Thus in this study, OPLS-DA provided a better way to demonstrate the differences in serum metabolites between groups [39].

Figures 5 and 6 are the results of the permutation tests from OPLS-DA between different groups. The values of the two parameters R2 and Q2, reflect the quality and reliability of the computed OPLS-DA model. R2 represents the goodness of fit, and Q2 represents the predictive ability of the model. The closer the two values are to 1 , the better the OPLS-DA model is in explaining the differences between groups [40].

The horizontal coordinate in the two figures represents the correlation coefficient to original values, and the vertical coordinate represents R2 and Q2 values. Green dots and blue squares represent the R2 and Q2 scores obtained by the permutation test. The two dotted lines represent regression lines for R2 and Q2. The intercept R2 in Figs. 5 and 6 were 0.984 and 0.92, respectively, and the intercept Q2 in Figs. 5 and 6 were 0.315 and -0.3 , respectively. The results showed that the OPLS-DA model was robust in reflecting the differences between groups, and overfitting was not a problem in this model.

\section{Results of differential metabolites and analysis}

As shown in Figs. 7 and 8, differential metabolites found by the analysis were summarized by volcano plots. Each point in the scatter plots represents a metabolite: The size of the points represents the VIP value in the OPLSDA model; The color of the points indicates whether the metabolites were significantly different between the two groups. Red indicates that the level of the metabolite was significantly higher in the model group compared with the normal group, and in the EI30 high-dose group compared with the model group; blue indicates the level of the metabolite was significantly lower; gray represents metabolites without statistically significant differential levels [35, 41].

The differential metabolites between the normal group and the model group, and between the EI30 high-dose group and the model group were selected from OPLSDA with VIP $>1$ and $P<0.05$ (See supplementary materials Table S1-S2). Table 6 illustrates that in total, 17 common differential metabolites with significance were found between the normal group and model group, and between the model group and EI30 high-dose group. It

Table 3 Contents of neurotransmitters $5-H T$ and GABA in brain tissues of mice $(n=10, \bar{x} \pm s)$

\begin{tabular}{llll}
\hline Group & Dosage $/ \mathrm{mg}^{*} \mathrm{~kg}^{-1}$ & $5-\mathrm{HT} / 10^{-2}$ & $\mathrm{GABA} / \mathrm{nmol} \cdot \mathrm{ng}{ }^{-1}$ \\
\hline Normal group & - & $3.91 \pm 0.73$ & $1.22 \pm 0.24$ \\
Model group & - & $2.58 \pm 0.20^{* *}$ & $1.77 \pm 0.18^{* *}$ \\
El30 high-dose group & 13.8 & $3.16 \pm 0.39^{\Delta \Delta}$ & $1.52 \pm 0.18^{* \Delta}$ \\
El30 medium-dose group & 6.9 & $3.37 \pm 0.56^{\Delta \Delta}$ & $2.00 \pm 0.32^{* *}$ \\
El30 low-dose group & 3.45 & $3.70 \pm 0.62^{\Delta \Delta}$ & $2.03 \pm 0.19^{* * \Delta}$ \\
\hline
\end{tabular}

Note: Compared with the normal group: ${ }^{*} P<0.05$, ${ }^{* *} P<0.01$. Compared with the model group: ${ }^{\triangle} P<0.05,{ }^{\triangle} P<0.01$ 
Table 4 Contents of excitatory neurotransmitters NE and DA in brain tissues of mice $(n=10, \bar{x} \pm s)$

\begin{tabular}{llll}
\hline Group & Dosage $/ \mathrm{mg}^{*} \mathrm{~kg}^{-1}$ & $\mathrm{NE} / 10^{-3}$ & $\mathrm{DA} / 10^{-3}$ \\
\hline Normal group & - & $10.95 \pm 1.01$ & $6.34 \pm 0.67$ \\
Model group & - & $18.90 \pm 1.86^{* *}$ & $11.25 \pm 2.26^{* *}$ \\
El30 high-dose group & 13.8 & $15.52 \pm 1.27^{* *}$ & $10.24 \pm 1.23^{* *}$ \\
El30 medium-dose group & 6.9 & $17.42 \pm 0.94^{* *}$ & $8.20 \pm 0.77^{* * \Delta}$ \\
El30 low-dose group & 3.45 & $17.75 \pm 2.14^{* * \Delta}$ & $9.18 \pm 1.09^{* *}$ \\
\hline
\end{tabular}

Note: Compared with the normal group: ${ }^{*} P<0.05$, ${ }^{* *} P<0.01$.Compared with the model group: ${ }^{\triangle} P<0.05,{ }^{\triangle \Delta} P<0.01$

is interesting to notice that the downregulation and upregulation of the 17 common differential metabolites showed regularities.

Among the 17 common differential metabolites, 15 of them, such as beta-mannosylglycerate 2, myristic acid, lauric acid, palmitoleic acid, 1-monopalmitin, were downregulated in the model group when compared with the normal group but upregulated in the EI30 high-dose group when compared with the model group. On the contrary, the other two differential metabolites, phthalic acid and trans-4-hydroxy-L-proline, were upregulated in the model group compared with the normal group but downregulated after the high-dose EI30 intervention.

\section{Analyses and results of metabolic pathways}

The differential metabolites between the normal group and model group and the differential metabolites between the model group and EI30 high-dose group (See supplementary materials Table S1-S2) were used for analyzing related metabolic pathways. Online analysis platform MetaboAnalyst3.0 (Http://www.metaboanalyst. $\mathrm{ca} /$ ) was used to analyze the relevant metabolic pathways. Mus musculus (KEGG) was used as the database. The identified pathways went through enrichment analysis (using hypergeometric distribution) and topology analysis (using relative-betweenness centrality). All metabolic pathways found displayed their impact values and $P$-values in the form of bubbles.

Figures 9 and 10 are the results of metabolic pathways found for the differential metabolites between the model group and the normal group, and between EI30 high-dose group and the model group, respectively. Every bubble in these figures represents a metabolic pathway. The size of the bubble and its position on the horizontal axis (represent the impact of pathways) shows the impact factor in topology analysis. The vertical coordinate and the color of the bubbles represent the $P$-value in the enrichment analysis. The darker the color, the smaller the $P$-value is. The cutoff value of the impact factor was set as 0.1 , and pathways of greater or equal value to this would be considered as relevant target pathways.

According to the analysis results in Fig. 9, seven relevant metabolic pathways were involved in PCPA induced insomnia in mice, which were biosynthesis of valine, leucine and isoleucine, metabolism of glyoxylic acid and dicarboxylic acid, metabolism of nicotine and niacinamide, tricarboxylic acid cycle, metabolism of starch sucrose, metabolism of riboflavin, and metabolism of phenylalanine. Based on the analysis results from Fig. 10, the

Table $\mathbf{5}$ Information of Identified compounds in El30 by LC-MS

\begin{tabular}{|c|c|c|c|c|c|c|}
\hline No. & $t_{R / \text { min }}$ & Molecular Formula & $\begin{array}{l}\text { Selected } \\
\text { ion }\end{array}$ & Experimental & Theoretical & Identification \\
\hline 1 & 4.74 & $\mathrm{C}_{23} \mathrm{H}_{29} \mathrm{NO}_{8}$ & {$[\mathrm{M}+\mathrm{H}]^{+}$} & 448.1981 & 448.1966 & 6-glc-coclaurine ${ }^{b}$ \\
\hline 2 & 5.93 & $\mathrm{C}_{19} \mathrm{H}_{24} \mathrm{NO}_{3}^{+}$ & $\mathrm{M}^{+}$ & 314.1746 & 314.1751 & Magnocurarine $^{a}$ \\
\hline 3 & 5.27 & $\mathrm{C}_{16} \mathrm{H}_{19} \mathrm{NO}_{8}$ & {$[\mathrm{M}-\mathrm{H}]^{-}$} & 353.1043 & 352.1038 & $\mathrm{~N}$-glc-indoleaceticacid ${ }^{\mathrm{b}}$ \\
\hline 4 & 7.41 & $\mathrm{C}_{20} \mathrm{H}_{24} \mathrm{NO}_{4}^{+}$ & $\mathrm{M}^{+}$ & 342.1697 & 342.1700 & Zizyphusine \\
\hline 5 & 7.65 & $\mathrm{C}_{23} \mathrm{H}_{32} \mathrm{O}_{15}$ & {$[\mathrm{M}-\mathrm{H}]^{-}$} & 547.1674 & 547.1668 & Sibiricoses A6 \\
\hline 6 & 9.31 & $\mathrm{C}_{24} \mathrm{H}_{26} \mathrm{O}_{14}$ & {$[\mathrm{M}-\mathrm{H}]^{-}$} & 537.1257 & 537.1250 & Sibiricaxanthone A \\
\hline 7 & 10.89 & $\mathrm{C}_{25} \mathrm{H}_{28} \mathrm{O}_{15}$ & {$[\mathrm{M}-\mathrm{H}]^{-}$} & 567.1363 & 567.1355 & Polygalaxanthone III \\
\hline 8 & 12.10 & $\mathrm{C}_{28} \mathrm{H}_{32} \mathrm{O}_{15}$ & {$[\mathrm{M}-\mathrm{H}]^{-}$} & 607.1679 & 607.1668 & Spinosin \\
\hline 9 & 21.70 & $\mathrm{C}_{34} \mathrm{H}_{42} \mathrm{O}_{19}$ & {$[\mathrm{M}-\mathrm{H}]^{-}$} & 753.2261 & 753.2247 & 3,6'-Disinapoylsucrose. \\
\hline 10 & 22.91 & $\mathrm{C}_{38} \mathrm{H}_{40} \mathrm{O}_{18}$ & {$[\mathrm{M}+\mathrm{H}]^{+}$} & 785.2288 & 785.2287 & 6"'-Feruloylspinosin \\
\hline 11 & 25.44 & $\mathrm{C}_{31} \mathrm{H}_{38} \mathrm{O}_{17}$ & {$[\mathrm{M}-\mathrm{H}]^{-}$} & 681.2050 & 681.2036 & Tenuifoliside A \\
\hline
\end{tabular}




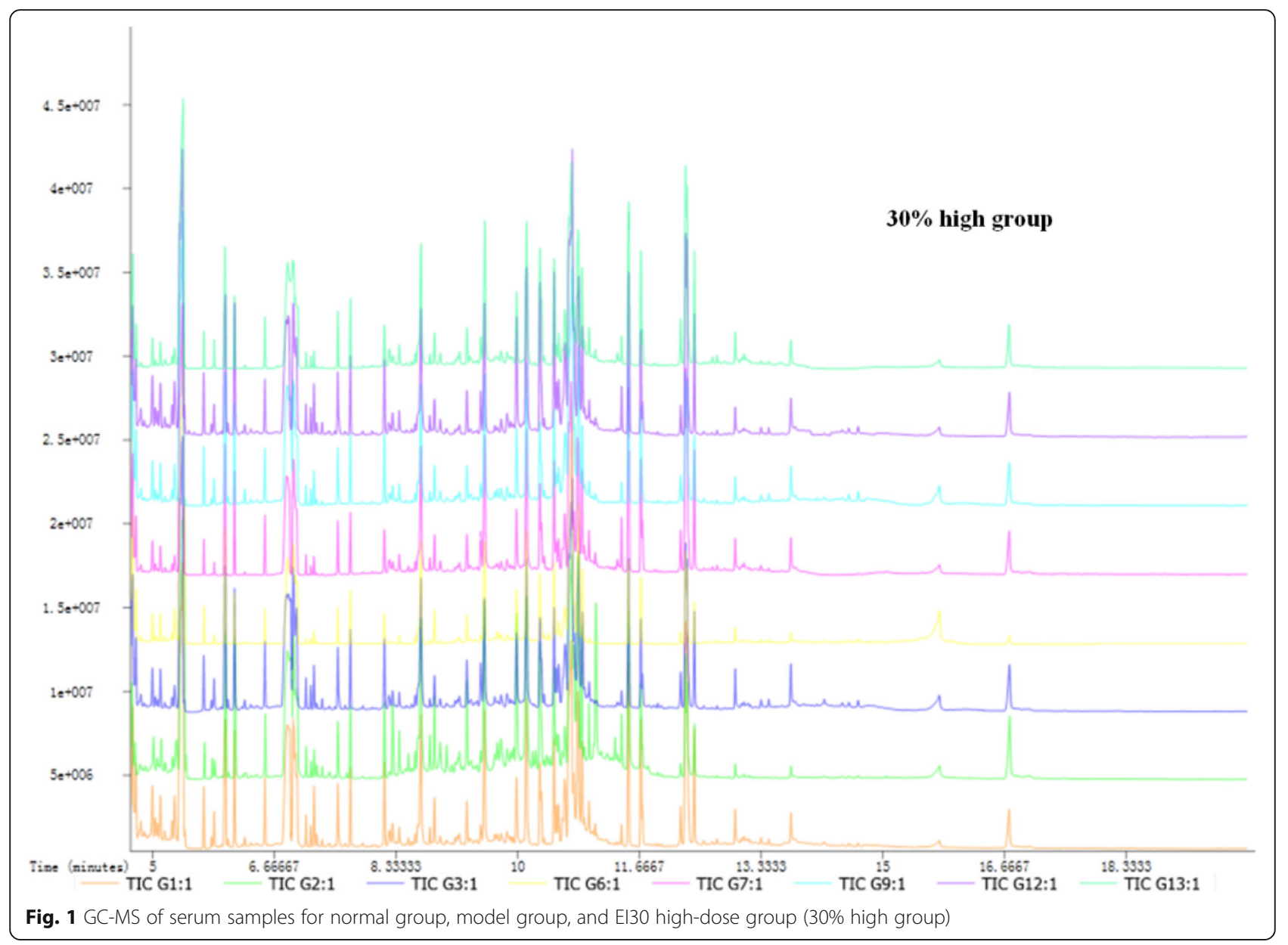

sedative-hypnotic effect of EI30 on PCPA induced insomnia in mice were related to five metabolic pathways, biosynthesis of valine, leucine, and isoleucine, metabolism of glyceride, metabolism of alanine, aspartic acid and glutamic acid, metabolism of phenylalanine, and metabolism of cysteine and methionine.

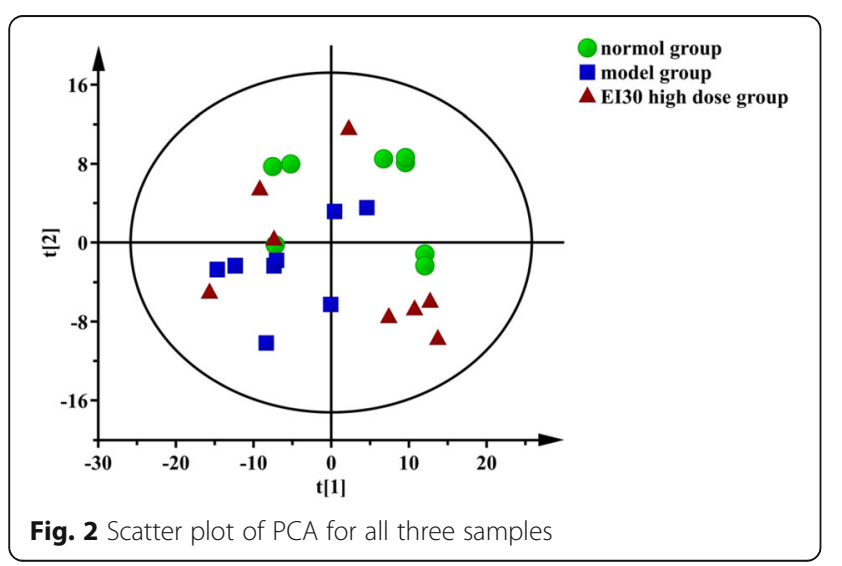

\section{Discussion}

Sedative-hypnotic effect of El30

Semen Ziziphi spinosae and Radix Polygalae are two herbs commonly used for sedative and hypnotic purposes in traditional Chinese medicine, and they are often used together as a pair [42]. In this research, we aimed

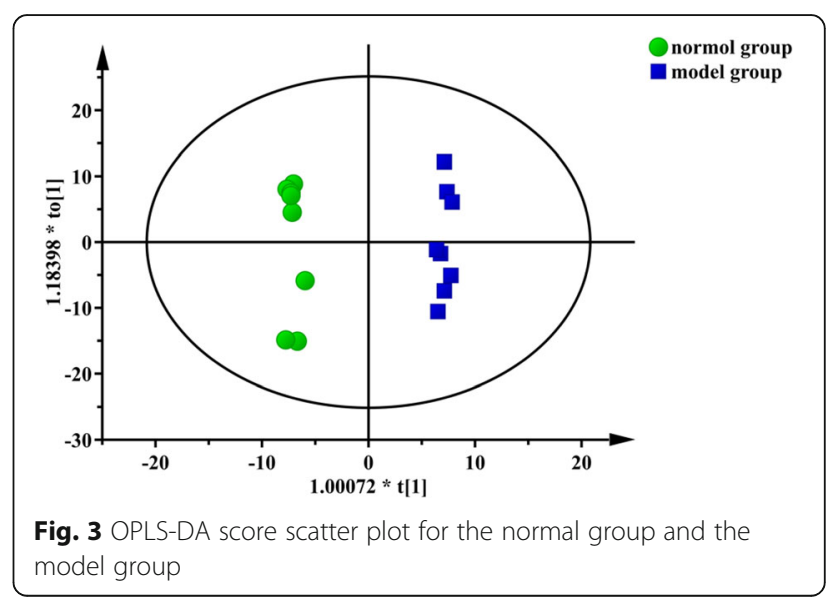




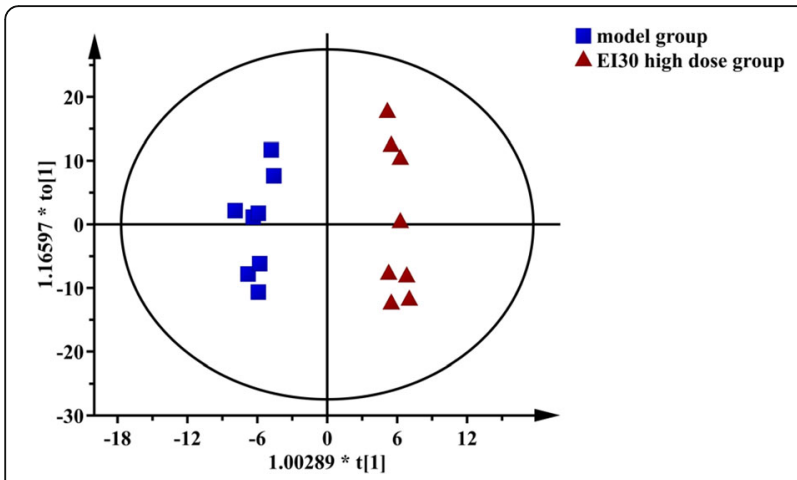

Fig. 4 OPLS-DA score scatter plot for the model group and El30 high-dose group

to study the sedative-hypnotic effect of this herbal pair and investigate its possible mechanism by studying EI30, the effective components of the herbal pair. The results showed that high-dose EI30 significantly increased the proportion of sleeping within $30 \mathrm{~min}$, and high, medium, and low-dose EI30 can significantly shorten sleep latency of pentobarbital sodium-induced sleep and prolong sleeping time, indicating that EI30 could promote sleep in mice, although the effect is still weaker when compared with Clonazepam. The results showed that the herbal pair had sedative-hypnotic effects, providing a research basis for the future development and utilization of this herbal pair.

Mechanism of the sedative-hypnotic effect of El30 on the treatment of insomnia

PCPA, a synthetic inhibitor of neurotransmitter 5-HT, can cause the disappearance of circadian rhythm and lead to insomnia, and it is well recognized to be used to create insomnia model [43]. In this experiment, mice were intraperitoneally injected with PCPA for three consecutive days, and after injection, the mice showed

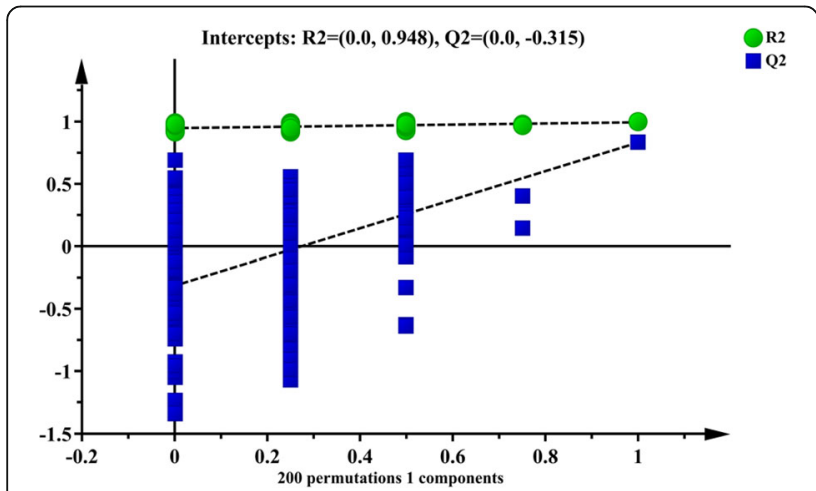

Fig. 5 OPLS-DA permutation test result between the normal group and the model group

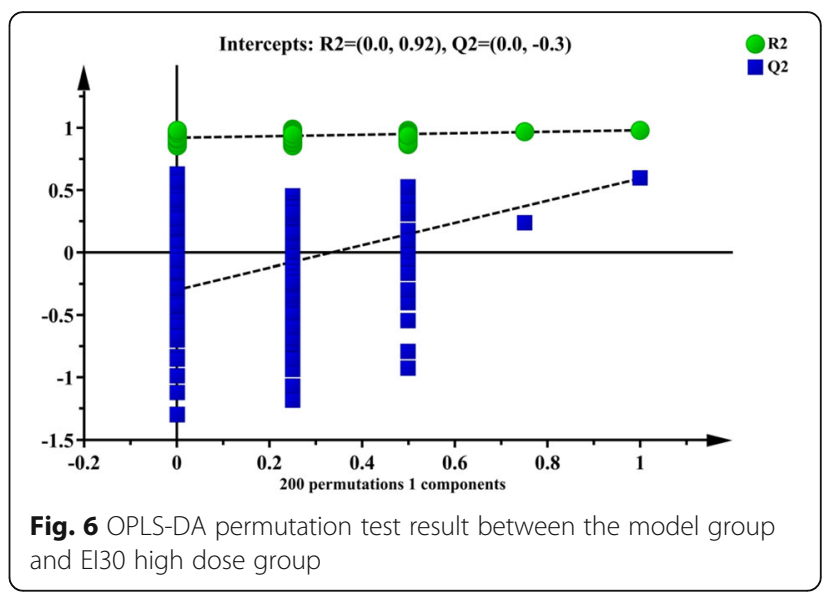

increased activity and sensitivity to sounds, the disappearance of circadian rhythm, and restlessness during the day, indicating successful model creation.

5 -HT is one of the vital neurotransmitters in the central nervous system, and an increase of 5-HT in the brain can encourage the occurrence of sleep [44]. The results of this study showed that EI30 could increase the proportion of 5-HT in the total protein in brain tissue in mice, suggesting that the sedative and hypnotic effect of EI30 is related to an increased level of 5-HT in the brain protein.

Neurotransmitter NE is mainly responsible for the central nervous excitement and awakening function, and it is related to fast wave sleep and can regulate the sleep-wake cycle [45]. The results in this study showed that EI30 reduced the proportion of NE in total protein in mouse brain tissue, showing that the sedativehypnotic effect of EI30 is related to the reduction of NE in brain protein.

GABA is an important inhibitory neurotransmitter in the central nervous system $[46,47]$. Increased level of GABA in the brain is associated with alleviation of anxiety, and it is of sedative-hypnotic effect $[48,49]$. However, findings of current studies on the changes in GABA level in the brain of insomnia models are divided. It is not clear whether sleep deprivation is associated with an increased or decreased level of GABA. The results of this study also showed inconsistent results. The content of GABA was significantly higher for the model group compared with the normal group, and EI30 highdose group had a significantly lower level of GABA compared with the model group, while the EI30 low-dose group showed a significantly higher level of GABA compared with the model group.

Another neurotransmitter DA also plays an important role in wakefulness. The excitation of DA neurons is related to an increased level of wakefulness [50]. The results of this study showed the effect of EI30 is also associated with the reduction of DA in the brain. 


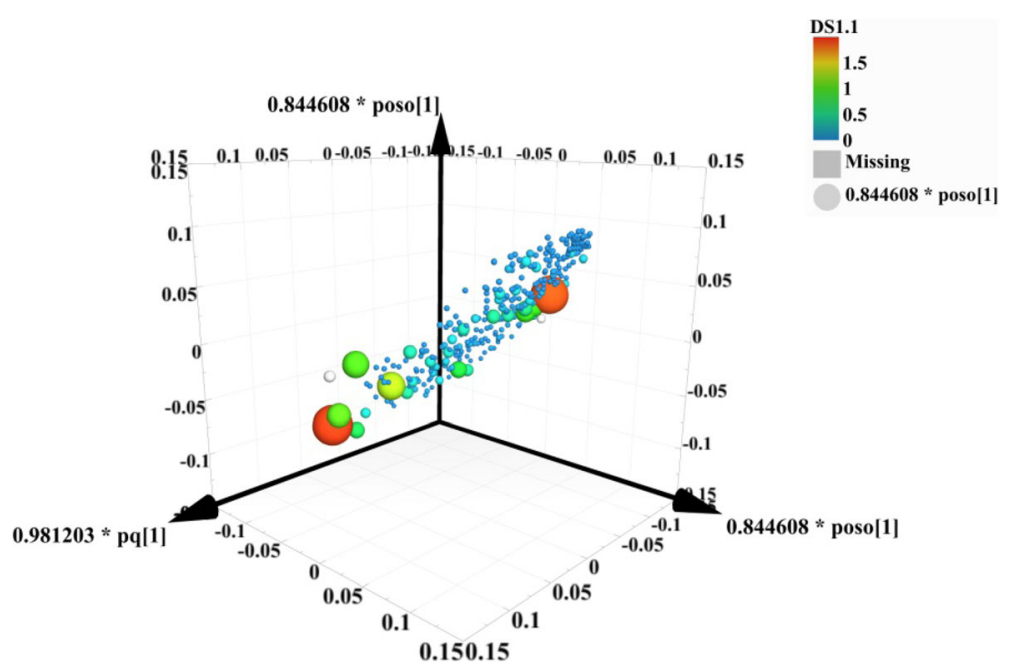

Fig. 7 Volcano plot of differential metabolites between the normal group and the model group

The results of this study showed that EI30 has a good sedative-hypnotic effect. This effect is possibly related to the adjustment of 5-HT, NE, GABA, and DA levels in mice brain.

\section{Effective components analysis}

Spinosin [13, 51] and jujuboside A [14] are the main monomer compounds of sedative-hypnotic effect in Semen Ziziphi spinosae. Radix Polygalae contains senegenin. Contents of spinosin, jujuboside $\mathrm{A}$, and senegenin in EI30 freeze-dried powder were determined in this study. The results showed that the contents of spinosin and senegenin were 1.61 and $0.61 \%$, respectively, but no jujuboside A was detected in EI30, as there was no spot at the corresponding positions of jujuboside A in TLC (Thin layer chromatography). However, in our study, other effective parts (solid obtained by $50 \%$ ethanol and
$70 \%$ ethanol in the gradient elution) were named EI50 and EI70. For EI50 and EI70, there were spots at the corresponding positions of jujuboside A, showing that jujuboside A was absent in EI30, but enriched in other effective parts like EI50 and EI70.

\section{Discussion on metabolism mechanisms of El30 sedative- hypnotic effect in vivo}

GC-MS is one of the most commonly used methods for metabolite analysis of biological samples in disease diagnosis and biomarker identification [52]. In this study, GC-TOF-MS, combined with multivariate analysis, were used to study the changes in serum metabolites of PCPA induced insomnia mice model under EI30 intervention.

By selecting results from OPLS-DA (VIP $>1$ and $P<$ $0.05)$, in total, 17 common differential metabolites were identified between the normal group and model group,

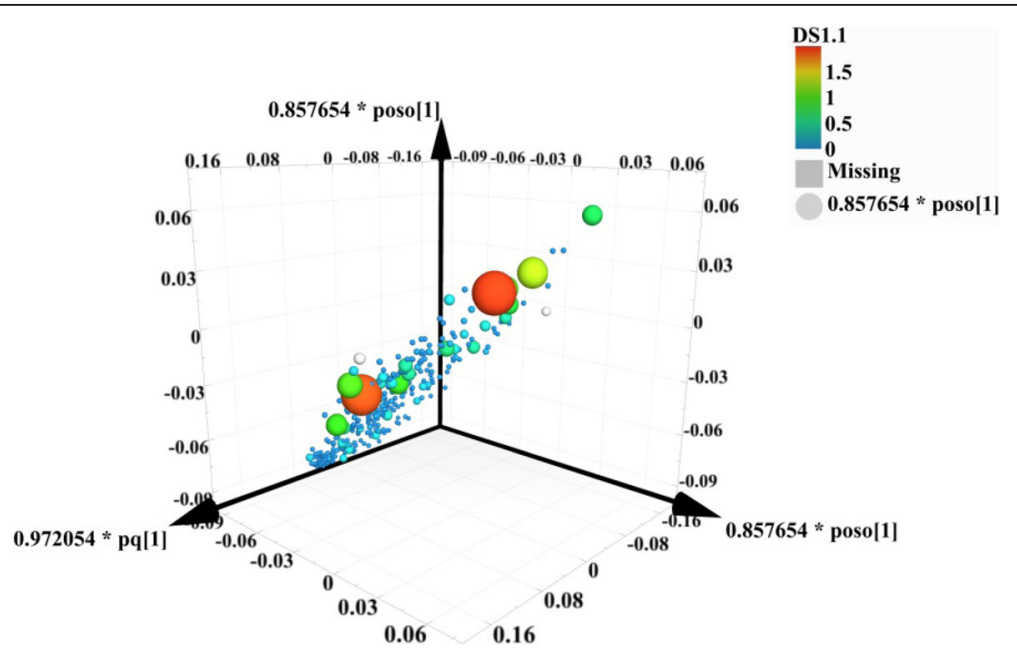

Fig. 8 Volcano plot of differential metabolites between the model group and El30 high-dose group 
Table 6 Common differential metabolites and variations

\begin{tabular}{llll}
\hline NO. & biomarkers & 模型组 $^{\mathrm{a}}$ & 高剂量组 $^{\mathrm{b}}$ \\
\hline 1 & beta-Mannosylglycerate 2 & $\downarrow$ & $\uparrow$ \\
2 & Myristic Acid & $\downarrow$ & $\uparrow$ \\
3 & lauric acid & $\downarrow$ & $\uparrow$ \\
4 & palmitoleic acid & $\downarrow$ & $\uparrow$ \\
5 & 1-Monopalmitin & $\downarrow$ & $\uparrow$ \\
6 & 5,6-dihydrouracil 1 & $\downarrow$ & $\uparrow$ \\
7 & palmitic acid & $\downarrow$ & $\uparrow$ \\
8 & pantothenic acid & $\downarrow$ & $\uparrow$ \\
9 & panthenol 2 & $\downarrow$ & $\uparrow$ \\
10 & phthalic acid & $\uparrow$ & $\downarrow$ \\
11 & pentadecanoic acid & $\downarrow$ & $\uparrow$ \\
12 & Isoleucine & $\downarrow$ & $\uparrow$ \\
13 & piceatannol 2 & $\downarrow$ & $\uparrow$ \\
14 & trans-4-hydroxy-L-proline 2 & $\uparrow$ & $\downarrow$ \\
15 & phenylacetaldehyde 2 & $\downarrow$ & $\uparrow$ \\
16 & D-Altrose 1 & $\downarrow$ & $\uparrow$ \\
17 & Sorbitol & $\downarrow$ & $\uparrow$ \\
\hline
\end{tabular}

(The $\uparrow \downarrow$ variations of differential metabolites for the model group column are results compared with normal group, and the $\uparrow \downarrow \downarrow$ variations for El30 high dose group are results compared with model group)

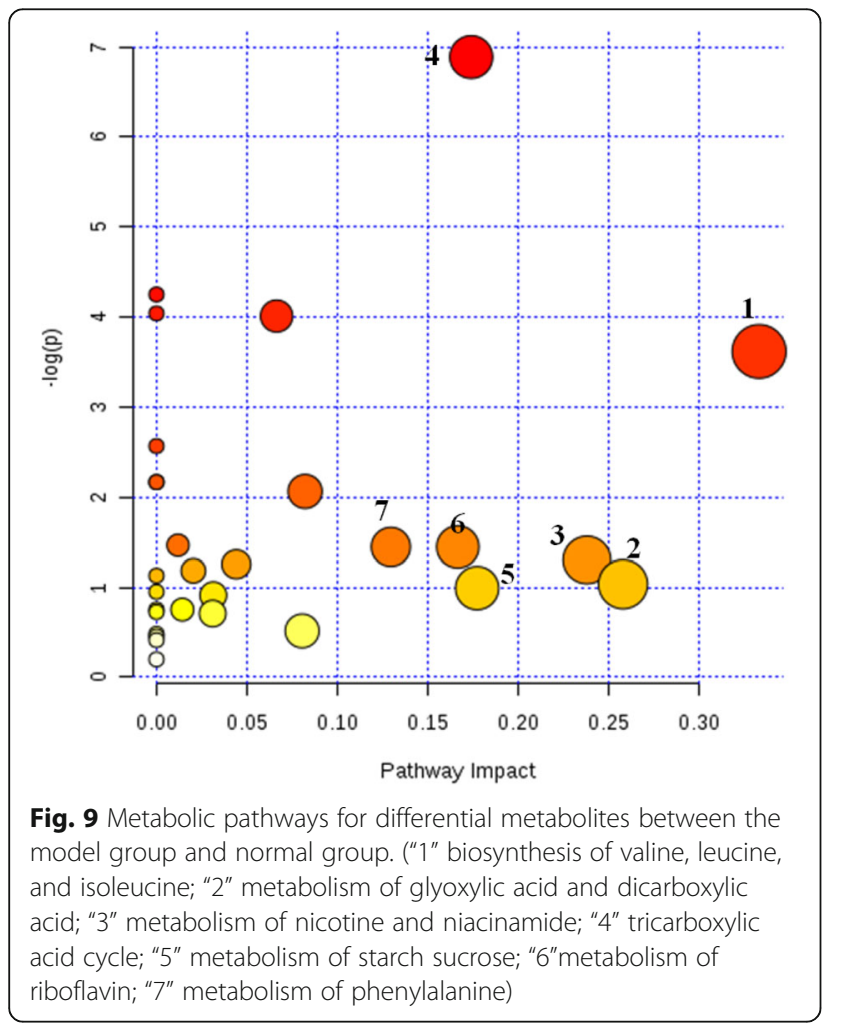

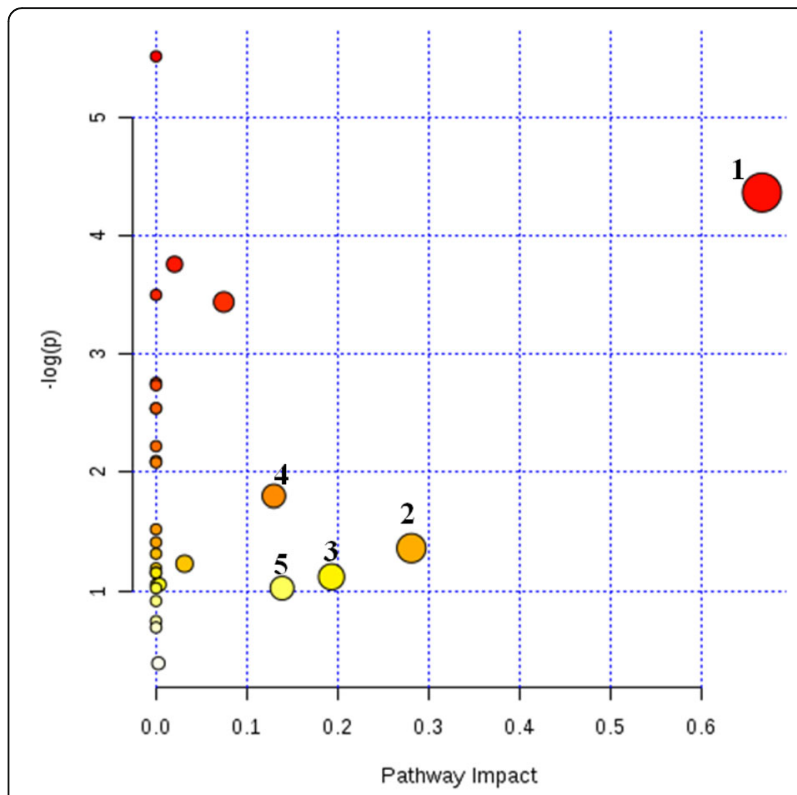

Fig. 10 Metabolic pathways for differential metabolites between El30 high-dose group and model group. ("1" biosynthesis of valine, leucine, and isoleucine; "2" metabolism of glyceride; "3" metabolism of alanine, aspartic acid, and glutamic acid; " 4 " metabolism of phenylalanine; " 5 " metabolism of cysteine and methionine)

and between the model group and EI30 high-dose group. They were beta-Mannosylglycerate 2, palmitoleic acid, phthalic acid, 1-Monopalmitin, inosine, and pantothenic acid. Five of them, beta-Mannosylglycerate 2, palmitoleic acid, 1-Monopalmitin, inosine, and pantothenic acid, were downregulated in the model group compared with the normal group but upregulated in the EI30 high-dose group compared with the model group. The other two, phthalic acid and trans-4-hydroxy-L-proline, were upregulated in the model group compared with the normal group and downregulated in EI30 high-dose group compared with the model group. The upregulation and downregulation of the common differential metabolites showed the successful production of the PCPA induced mice model of insomnia and the effectiveness of the metabolic regulation of high-dose EI30 intervention.

The results of metabolic pathway analysis showed that the seven metabolic pathways involved in mice insomnia induced by PCPA were biosynthesis of valine, leucine, and isoleucine, metabolism of glyoxylic acid and dicarboxylic acid, metabolism of nicotine and niacinamide, tricarboxylic acid cycle, metabolism of starch sucrose, metabolism of riboflavin, and metabolism of phenylalanine. The sedative-hypnotic effects of EI30 on PCPA induced insomnia in mice were related to five metabolic pathways, biosynthesis of valine, leucine, and isoleucine, metabolism of glyceride, metabolism of alanine, aspartic acid, and glutamic acid, metabolism of phenylalanine, and metabolism of cysteine and methionine. 
This study showed that two metabolic pathways were involved in metabolic regulations of both insomnia and the EI30 intervention, which were biosynthesis of valine, leucine, and isoleucine and metabolism of phenylalanine. Findings from a previous study showed that in the PCPA insomnia model, the biosynthetic pathway of valine, leucine and, isoleucine was upregulated, and after proper drug intervention, this metabolic pathway was tending to be normal [53]. The similar results were obtained in this study.

Valine, leucine, and isoleucine are essential amino acids for the human body, which are involved in the stress response, energy metabolism, and muscle metabolism process [54]. Valine is of neuroprotective effect, and leucine is essential in muscle metabolism [54]. Leucine deficiency can lead to muscle tremors [54]. Therefore, the PCPA induced insomnia model is possibly related to nerve injury and increased glucose metabolism. The results of this study showed that EI30 has a regulatory effect on the abnormal metabolism of leucine and isoleucine caused by PCPA and can make the metabolism of valine, leucine, and isoleucine tend to be normal.

Phenylalanine can produce tyrosine via phenylalanine hydroxylase, and tyrosine is essential for the production of neurotransmitter DA $[55,56]$. Dopamine is essential for the production of NE [57]. DA and NE are the key neurotransmitters that cause insomnia. The results of serum metabolomics in this study showed that PCPA could lead to abnormal phenylalanine metabolism. The EI30 intervention downregulated the production of phenylalanine. There were previous serum metabolomics findings that the sedative-hypnotic effect of Semen Ziziphi spinosae was related to correcting phenylalanine metabolism disorder caused by PCPA [39]. The findings in this study showed that the levels of DA and NE in the model group were significantly higher compared with the normal group, but in the EI30 intervention group, the levels of both were decreased. Based on these findings, it is speculated that PCPA is causing insomnia by inhibiting the synthesis of 5-HT, disrupting the metabolism of monoamine neurotransmitters. While EI30 may play a sedative-hypnotic role by regulating the metabolism of phenylalanine, thereby inhibiting the synthesis of excitatory neurotransmitter DA and NE.

\section{Conclusions}

This study evaluated the sedative-hypnotic effect of herbal pair Semen Ziziphi spinosae and Radix Polygalae by animal experiments, and the main chemical compounds in the effective components of herbal pair were identified. The results of this study identified the possible mechanisms of insomnia induced by PCPA and biomarkers helpful for the early diagnosis. Also, the study was the first to preliminary investigate the metabolism mechanisms of the sedative-hypnotic effect of the combination of Semen Ziziphi spinosae and Radix Polygalae by metabolomics approach, providing a research basis for the future development and utilization of this herbal pair in the treatment of insomnia.

\section{Supplementary information}

Supplementary information accompanies this paper at https://doi.org/10. 1186/s12906-020-03000-8.

\section{Additional file 1: Table S1-S2}

\section{Abbreviations}

5-HT: 5-hydroxytryptamine; DA: dopamine; GABA: gamma-aminobutyric acid; GC-TOF-MS: gas chromatography time-of-flight mass spectrometry; LCMS: liquid chromatography-mass spectrometry; NE: norepinephrine; OPLSDA: orthogonal projections to latent structures discriminant analysis; PCA: principal components analysis; PCPA: para-chlorophenylalanine; QC: quality control

\section{Acknowledgements \\ Not applicable.}

Ethics approval.

\section{Authors' contributions}

SSJ, LH participated in drafting, writing the manuscript. WY assisted with the animal experiments and drafted and finalized all figures and tables. WYL assisted with the design and performance of this study and reviewed the manuscript. All authors approved the final version of the manuscript.

\section{Funding}

Research Project of Health and Family Planning Commission of Shanxi Province, (201601109). Open Project of Shanxi Province Key Laboratory of TCM Encephalology (CME-OP-2017005). Shanxi Education Science "1331 Project" special research project (Research and Development of Traditional Chinese Medicine Microemulsion and New Biological Preparation). Shanxi Provincial Department of Education 2019 Graduate Education Innovation Program (2019SY504). The funders had no role in study design, data collection and analysis, decision to publish, or preparation of the manuscript.

\section{Availability of data and materials}

The datasets used and/or analysed during the current study are available from the corresponding author on reasonable request.

Ethics approval and consent to participate

Ethical approval for using experimental animals for this study had been obtained from the Medical Ethics Committee of Shanxi University of Chinese Medicine (Approval number: 2019LL129). All experimental procedures in this study were under ethical standards of the Medical Ethics Committee of Shanxi University of Chinese Medicine. (See in additional files attached (in Chinese)).

\section{Consent for publication}

Not applicable.

\section{Competing interests}

The authors declare that they have no conflict of interest.

Received: 29 September 2019 Accepted: 22 June 2020

Published online: 02 July 2020

References

1. Tan YL, Sun H, Sun WJ, Zhang AH, Wang XJ. Research progress on the chemical constituents and pharmacological effects of semen aiziphi spinosae. Lishizhen Med. Mater. Med. Res. 2014;25(1):186-8 (in Chinese). 
2. Mao $Y Q$, Yao $X$, Chen L. Determination of underivatized amino acids from Ziziphi Spinosae semen by HILIC-HPLC-MS /MS. Chin J Exp Tradit Med Formulae. 2016;21:67-72 (in Chinese).

3. You JS, Peng M, Shi JL, Zheng HZ, Liu Y, Zhao BS, et al. Evaluation of anxiolytic activity of compound Valeriana jatamansi Jones in mice. BMC Complementary Altern Med. 2012;12(1):223.

4. Yang Y, Qiao W, Liu JS, Ren LY, Sun Y. Study on compatibility of antidepressant active components in semen Ziziphi spinosae. Lishizhen Med Mater Med Res. 2012;23(1):7-8 (in Chinese).

5. Si QQ, Niu XH, Li JY. Effect of jujuboside A on glomerular cell apoptosis in diabetic model rats. Chin J Pharmacol Toxicol. 2017;31(5):399-404 (in (hinese).

6. Liu Z, Zhao X, Liu B, Liu AJ, Li H, Mao X, et al. Jujuboside A, a neuroprotective agent from semen Ziziphi spinosae ameliorates behavioral disorders of the dementia mouse model induced by $A \beta 1-42$. Eur J Pharmacol. 2014;738:206-13.

7. Lang J. Effect of polysaccharides in wild Jujube on mouse immunity. Food Res. Dev. (Tianjin, China). 2013;34(4):35-6 (in Chinese).

8. Zhang Y. Study on sedation of semen Ziziphi spinosae effective fraction [Master's thesis]. Jilin Agricultural University. 2013; (in Chinese).

9. Cao JX, Zhang QY, Cui SY, Cui XY, Zhang J, He ZY, et al. Hypnotic effect of jujubosides from semen Ziziphi spinosae. J Ethnopharmacol. 2010;130(1): 163-6.

10. Chen KX, Zhao LM, Ji CJ, Tan NH. Flavone C-glycosides from seeds of Ziziphus jujuba var.spinosa. China J. Chin. Mater Med. 2015;40(8):1503-7 (in (hinese).

11. Wang J, Ni J, Qu WM. Spinosin induced non-rem sleep in mice. Chin. J. Pharmacol. Toxicol. 2016;30(10):1018 (in Chinese).

12. Wang LE, Cui XY, Cui SY, Cao JX, Zhang J, Zhang YH, et al. Potentiating effect of spinosin, a C-glycoside flavonoid of semen Ziziphi spinosae, on pentobarbital-induced sleep may be related to postsynaptic 5-HT1A receptors. Phytomedicine. 2010;17(6):404-9.

13. Liu J, Zhai WM, Yang YX, Shi JL, Liu QT, Liu GL, et al. GABA and 5-HT systems are implicated in the anxiolytic-like effect of spinosin in mice. Pharmacol., Biochem. Behav. 2015;128:41-9.

14. Liu XY. The effect of jujuboside A on the sleep of drosophila melanogaster Heilongjiang University Of Chinese Medicine [Dissertation]. Heilongjiang University of Chinese Medicine. 2016. (in Chinese).

15. Fu JW, Qiao WD, Chen ZH. Study on sedative and hypnotic effects of total alkaloids from semen Ziziphi spinosae. J Tianjin Med University. 2005;11(01): 52-4 (in Chinese).

16. Zhang YQ, Qiao LD, Song MY, Wang L, Xie J, Feng H. Hplc-ESI-MS/MS analysis of the water-soluble extract from semen Ziziphi spinosae and its ameliorating effect of learning and memory performance in mice. Pharmacogn Mag. 2014;10(40):509-16.

17. Li Z, Ren S, Chang ZR, Yan HX, Chen YG, Fu XT. Content comparison of three components in Ziziphi Spinosae semen pieces. Chinese J New Drugs. 2017;1:91-6 (in Chinese).

18. Cui SJ, Luo J, Ma TC. UPLC Fingerprint of Ziziphi Spinosae Semen. Chin. Pharm. J. (Beijing, China). 2013;48(7):509-11 (in Chinese).

19. Liu PP. Determination of chemical constituents and four saponins in semen Ziziphi spinosae [Master's thesis]. Beijing University of Chinese Medicine. 2013; (in Chinese)

20. Sun XP, Li SD, Shi Z, Li TF, Pan RL, Chang Q, et al. Antidepressant-like effects and memory enhancement of a herbal formula in mice exposed to chronic mild stress. Neurosci Bull. 2013;29(6):737-44.

21. Huang Y, Chen YQ, Chen Q, Hu GY, Cao YG, Xu XT. Protective effect of Tenuigenin on structure and function of mitochondria of hippocampal neurons in dementia rats induced by A 1-40. Pharmacol Clin Chin Mater Med. 2015;1:93-7 (in Chinese).

22. Guo YF, Li XY, Huo F, Cao DJ. Effects of Radix Polygalae on learning and memory and long-term potentiation of hippocampus in rats with D-galactose induced senility. Chin J Gerontol. 2011;31(4):632-24 (in Chinese).

23. Sur B, Lee B, Yoon YS, Lim P, Hong R, Yeom M, et al. Extract of Polygala tenuifolia alleviates stress-exacerbated Atopy-like skin dermatitis through the modulation of protein kinase A and p38 mitogen-activated protein kinase signaling pathway. Int J Mol Sci. 2017:18(1):190.

24. Jin SN, Study on the Chemical constituents of Xiye Polygala (polygala tenuifolia Wild.) on sedative effect [Master's thesis]. Hubei University of Chinese Medicine. 2011. (in Chinese).
25. Cao Q, Jiang Y, Cui SY, Tu PF, Chen YM, Ma XL, et al. Tenuifolin, a saponin derived from Radix Polygalae, exhibits sleep-enhancing effects in mice. Phytomedicine. 2016;23(14):1797-805.

26. Lee Cl, Han JY, Hong JT, Oh KW. 3, 4, 5-Trimethoxycinnamic acid (TMCA), one of the constituents of Radix Polygalae enhances pentobarbital-induced sleeping behaviors via GABA A ergic systems in mice. Arch Pharm Res. 2013; 36(10):1244-51.

27. Chen X. Studies on the mechanism of 3,6'-disinapoyl sucrose promoting neuronal regeneration and neuroprotective effect on depression [Master's thesis]. Shanxi University of medicine. 2011; (in Chinese).

28. Li YH, Li GM, Qu FJ. Experience of HUANG Yan on treating encephalopathy with TCM pair drugs. Chin Arch Tradit Chin Med. 2016;34(6):1309-12 (in Chinese).

29. Li Q, Du CH, Zhang M, Yan Y, Gao Y, Qin XM. Investigation of effective components screening of Ziziphi Spinosae semen based on serum pharmacochemistry and network pharmacology. Chin Tradit Herb Drugs. 2017:48(10):1936-43 (in Chinese).

30. Pharmacopoeia of the People's Republic of China: 2015 Edition. Four volumes 2015. (in Chinese).

31. Gou YJ. Study on the extraction process and quality control standard of the QiGuanYan KeLi [Master's thesis]. Lanzhou University2016. (in Chinese).

32. He Y, Mao C, Chen Z, Wen H, Lu W, Wu H. Identification of differential metabolites in liquid diet fermented with Bacillus subtilis using gas chromatography time of flight mass spectrometry. Animal Nutrition. 2016; 2(4):351-6.

33. Chong IG, Jun CH. Performance of some variable selection methods when multicollinearity is present. Chemom Intell Lab Syst. 2005;78(1-2):103-12.

34. Quintás G, Portillo N, García-Cañaveras JC, Castell JV, Ferrer A, Lahoz A. Chemometric approaches to improve PLSDA model outcome for predicting human non-alcoholic fatty liver disease using UPLC-MS as a metabolic profiling tool. Metabolomics. 2012;8(1):86-98.

35. Saccenti E, Hoefsloot HCJ, Smilde AK, Westerhuis JA, Hendriks MMWB Reflections on univariate and multivariate analysis of metabolomics data. Metabolomics. 2014;10(3):361-74.

36. Zhang JJ. Studies on the extraction, isolation, purification of Radix Polygalae glycoprotein and its anti-aging activity in vivo and vitro [Master's thesis]. Shanxi University of Chinese Medicine. 2017; (in Chinese).

37. Eriksson L, Antti H, Gottfries J, Holmes E, Johansson E, Lindgren F, et al. Using chemometrics for navigating in the large data sets of genomics, proteomics, and metabolomics (gpm). Anal Bioanal Chem. 2004;380(3):41929.

38. Chi A, Zhang Y, Kang Y, Shen Z. Metabolic mechanism of a polysaccharide from Schisandra chinensis to relieve chronic fatigue syndrome. Int. J. Biol. Macromol. 2016;93(Pt A):322-32.

39. Trygg J, Wold S. Orthogonal projections to latent structures (O-PLS). J Chemometrics. 2002;16(3):119-28.

40. Zhang XL, Xu L, Shen JM, Cao B, Cheng T, Zhao T, et al. Metabolic signatures of esophageal cancer: NMR-based metabolomics and UHPLCbased focused metabolomics of blood serum. Biochim Biophys Acta. 2013; 1832(8):1207-16.

41. Tobias K, Gert W, Do Yup L, Yun L, Mine P, Sevini S, et al. FiehnLib: mass spectral and retention index libraries for metabolomics based on quadrupole and time-of-flight gas chromatography/mass spectrometry. Anal Chem. 2009:81(24):10038-1048.

42. Wu LM. Textual research on the herbal and function of Spina date Spinosae. J Chin Med Mater. 2005;28(5):432-4 (in Chinese).

43. Xiao CR, Ma ZC, Li HJ, et al. Phase II enzymes activity induced by curcumin accompanying translocation of Nrf2 and activation of ARE binding activity. J Toxicol. 2007:4:326-7 (in Chinese).

44. Ji WB. Studies on the pharmacodynamics and mechanisms of sedativehypnotic of extracts semen Ziziphi spinosae and Fructus Schisandrae Chinensis [Master's thesis]. Anhui University of Chinese Medicine 2013 (in Chinese).

45. Mitchell HA, Weinshenker D. Good night and good luck: norepinephrine in sleep pharmacology. Biochem Pharmacol. 2010;79(6):801-9.

46. Huang MP, Radadia K, Macone BW, Auerbach SH, Datta S. Effects of eszopiclone and zolpidem on sleep-wake behavior, anxiety-like behavior and contextual memory in rats. Behav Brain Res. 2010;210(1):54-66.

47. Sorra K, Chen C-S, Chang C-F, Pusuluri S, Mukkanti K, Wu C-R, et al. Synthesis, anticonvulsant, sedative and anxiolytic activities of novel annulated pyrrolo [1,4] benzodiazepines. Int J Mol Sci. 2014;15(9):16500-10. 
48. Ning L, Liu J, Wang M, Yu Z, Zhu K, Gao J, et al. Sedative and hypnotic effects of Schisandrin B through increasing GABA/Glu ratio and upregulating the expression of GABA A in mice and rats. Biomed Pharmacother. 2018;103:509-16.

49. Xu Q, Qu WM, Huang ZL. Progress in sleep-wake regulation of dopamine D_2 receptor. Chin. J. Clin. Pharmacol. Ther. 1999:4(1).

50. Pastukhov IF, A lu C, lakimchuk AA, Ekimova IV, Romanova IV, Khudik KA. Sleep changes during degeneration of neurons in the substantia nigra induced by inhibitor of proteasomes lactacystin in rats. Rossiǐskii Fiziologicheskiĭ Zhurnal Imeni Imsechenova 2010;96(12):1190-1202.

51. Wang LE, Cui XY, Cui SY, Cao JX, Zhang J, Zhang YH, et al. Potentiating effect of spinosin, a C-glycoside flavonoid of semen Ziziphi spinosae, on pentobarbital-induced sleep may be related to postsynaptic 5-HT (1A) receptors. Phytomedicine. 2010;17(6):404-9.

52. Hua Y, Xue W, Zhang M, Wei Y, Ji P. Metabolomics study on the hepatoprotective effect of polysaccharides from different preparations of Angelica sinensis. J Ethnopharmacol. 2014;151(3):1090-9.

53. Liu GH. Study on the target metabolomics of sedative and hypnotic effects of Jiaotaiwan [Master's thesis]. Guangzhou University of Chinese Medicine2015. (in Chinese).

54. Etzel MR. Manufacture and use of dairy protein fractions. J. Nutr. 2004; 134(4):996S-1022s.

55. Manfridi A, Brambilla D, Mancia M. Sleep is differently modulated by basal forebrain GABAA and GABAB receptors. Am J Phys Regul Integr Comp Phys. 2001;281(1):R170-R5

56. Han BH, Park MH. Alkaloids are the sedative principles of the seeds ofZizyphus vulgaris var. spinosus. Arch. Pharmacal Res. 1987;10(4):203.

57. Diao YM. Study on the effect of anmei decoction on promoting sleep and its mechanism [dissertation]. Guangzhou University of Traditional Chinese Medicine 2010. (in Chinese).

\section{Publisher's Note}

Springer Nature remains neutral with regard to jurisdictional claims in published maps and institutional affiliations.

Ready to submit your research? Choose BMC and benefit from:

- fast, convenient online submission

- thorough peer review by experienced researchers in your field

- rapid publication on acceptance

- support for research data, including large and complex data types

- gold Open Access which fosters wider collaboration and increased citations

- maximum visibility for your research: over $100 \mathrm{M}$ website views per year

At $\mathrm{BMC}$, research is always in progress.

Learn more biomedcentral.com/submissions 